\title{
EARLY NEOLITHIC POTTERY COMPLEX OF THE UPPER VOLGA CULTURE FROM SITE ZAMOSTJE 2: TYPOLOGICAL COMPOSITION AND CHRONOLOGICAL FRAMES
} (C)2014

V. M.Lozovski, candidate of history sciences, senior researcher, Paleolithic Department, Institute for the History of material culture St.-Petersbourg, St.-Petersbourg (Russia)

Sergiev-Posad History and Art museum Sergiev Posad, (Russia)

O. V.Lozovskaya, candidate of history sciences, researcher, Experimental and Use-wear analysis laboratory

Institute for the History of material culture St.-Petersbourg, St.-Petersbourg (Russia), Sergiev-Posad History and Art museum Sergiev Posad (Russia)

G. I. Zaitceva, , candidate of chemistry sciences, senior researcher, Laboratory of archaeological technologies

Institute for the History of material culture RAS St.Petersburg, (Russia)

Göran Possnert, Professor, doctor, The Angström Laboratory

University of Uppsala, Uppsala (Sweden)

M. A. Kulkova, candidate of geological and mineralogical sciences, associate professor of the Department of Geology and geoecology

Herzen State Pedagogical University, St.Petersburg (Russia)

Russian State Pedagogical University, St.Petersburg (Russia)

Annotation: The paper describes the complex of Early Neolithic Upper Volga culture pottery from site Zamostje 2. The analysis revealed that the vast majority of ceramics found during the excavation of site belong to the first stage of development of the Upper Volga culture - ceramics without ornaments and fragments with ornaments comprised of small dots and notches. Conducted extensive radiocarbon dating by different kinds of materials made it possible to determine the time of existence of the Upper Volga culture on the site Zamostje 2 within the 6850 - 6200 BP. Nevertheless, a small series of dates obtained from crust on fragments, demonstrates a more ancient age as compared with the main array of dates. The nature of such phenomenon currently not entirely clear .

Keywords: Early Neolithic; Upper Volga culture; the Volga-Oka region; radiocarbon dating

\section{УДК 902.2}

\section{НАЧАЛО РАСПРОСТРАНЕНИЯ ТЕХНОЛОГИИ ИЗГОТОВЛЕНИЯ ГЕОМЕТРИЧЕСКИХ МИКРОЛИТОВ «СО СТРУГАНЫМИ СПИНКАМИ»}

(C) 2014

B.A. Манько, кандидат исторических наук, старший научный сотрудник отдела археологии Крыма Институт археологии НАН Украины, Киев (Украина)

Аннотация: Автор анализирует процесс появления и распространения геометрических микролитов с плоской отжимной дорсальной ретушью на территории Ближнего и Среднего Востока, в бассейне Восточного Средиземноморья и в Восточной Европе. Рассматривается типология указанных изделий, их роль в комплексах неолита Восточной Европы. На основе анализа типологии и технологии изготовления устанавливаются первичные и вторичные очаги распространения новой технологии.

Ключевые слова: неолит; отжимная техника расщепления; геометрические микролиты с дорсальной струйчатой ретушью; микролиты с «гелуанской» ретушью.

Появление и распространение специфических форм геометрических микролитов «со стругаными спинками» стали причиной такой ситуации на территории Восточной Европы, когда традиционный подход для культурной дифференциации различных феноменов, основанный на анализе комплексов геометрических микролитов, выявил существенные недостатки. Распространение геометрических микролитов, изготовленных даже с применением разных технологий, привело к распространению подобных типов, слабо различающихся по внешнему виду. В результате появились теории о конвергентном развитии неолитических культур, о стирании граней между различными культурами в неолите, об утрате информативности каменных индустрий для процедуры индикации культурных явлений. Так, Д.Ю. Нужный пишет об утрате типологического разнообразия геометрических микролитов [1, с.78].

Тем не менее, история распространения указанных специфических типов микролитов является важной для понимания культурно-исторических процессов на территории Восточной Европы. Хронология распространения явления очень ярко иллюстрирует процессы миграций, культурного обмена между населением как смежных, так и удаленных регионов, последовательность процессов вовлечения отдельных групп населения в систему распространения неолитических инноваций.
Для переосмысления многочисленных комплексов геометрических микролитов со «стругаными спинками» в качестве информативного археологического источника нам необходимо описать их типологическое многообразие, которое в реальности все же существует, выяснить историю формирования типа в каждом регионе. Только после этого, используя метод корреляции с данными абсолютной хронологии, мы сможем использовать данный тип изделий как полноценный источник для реконструкции культурно-исторического процесса.

Геометрический микролит со струганой спинкой - это изделие из пластинчатой заготовки, а именно - из медиальной части заготовки либо из целой пластины или пластинки, со струйчатой дорсальной ретушью, нанесенной отжимным способом. Для изготовления геометрических микролитов на территории Восточной Европы использовались пластинчатые заготовки, полученные исключительно отжимным способом. На территории Ближнего и Среднего Востока заготовками могли быть также пластины, полученные традиционным ударным методом. В комплексах Ближнего и Среднего Востока известны только трапеции и треугольники «со стругаными спинками», европейские комплексы демонстрируют большее типологическое разнообразие: включают также сегменты и ромбы.

Для построения типологии мы используем следующие 
параметры:

Форма микролитов. Трапеции, ромбы, параллелограммы, треугольники, сегменты, черешковые трансверсальные наконечники.

Вид заготовки, используемой для изготовления геометрического микролита. Этот параметр имеет важнейшее значение, поскольку позволяет относить к разным типам даже такие изделия, которые визуально являются абсолютно одинаковыми. По виду заготовки мы отличаем пластины и пластинки, а по методу их получения мы указываем на возможность использования отжимной техники расщепления. Последнее возможно далеко не всегда. Заготовками могут быть медиальные части пластинчатых заготовок или целые пластины.

Угол продольной оси заготовки по отношению к широкому лезвию. Широкое лезвие может быть перпендикулярным, параллельным, расположенным под углом по отношению к продольной оси.

Параметры и пропорции. Мы должны различать низкие, средневысокие и высокие геометрические микролиты.

Вид ретуши, покрывающей дорсальную поверхность. Возможно использование чешуйчатой и струйчатой ретуши. Чешуйчатая ретушь может наноситься разными способами. Струйчатая ретушь наносится исключительно отжимным способом, длина фасетки всегда в два раза больше ширины. Возможны комбинации разных видов ретуши.

Отношение площади, покрытой ретушью, к площади дорсальной поверхности. Мы различаем микролиты, имеющие ретушь, заходящую на спинку, покрывающую дискретные части дорсальной поверхности; ретушь, образующую целиком ретушированный участок дорсальной поверхности; ретушь, полностью покрывающую дорсальную поверхность заготовки.

Характер оформления краев геометрических микролитов. На практике мы наблюдаем следующие варианты: наличие полукрутой ретуши с вентральной стороны, наличие крутой ретуши по краям или по дуге, неретушированные изломы заготовок, края, полностью съеденные отжимной ретушью.

Характер оформления нерабочего основания (касается всех микролитов, кроме сегментов). Может иметь ретушь, выемки, зубцы.

Развитие технологии плоского ретуширования дорсальной поверхности геометрических микролитов.

Хронологические рамки исследования. В истории человечества подобные типы изделий возникали неоднократно. На территории Восточной Европы нам известны похожие изделия на стоянке Буран-Кая III (слой C), который датируется приблизительно 36-32 kyr BP [2, c.140]. В области распространения докерамического неолита А аналогами трапеций со стругаными спинками являлись так называемые вкладыши Native Hugdud, бытовавшие в IX тыс. до н.э. [3, p.113]. Но такого рода технологические прорывы не связаны с рассматриваемым периодом. В двух указанных случаях мы не видим начала устойчивой технологической традиции, выходящей за рамки тех индустрий, в которых такие инновации и появлялись, и исчезали. Нас интересуют только те технологии и артефакты, которые появившись в VII тыс. до н.э. в ареалах ограниченного числа каменных индустрий, а затем распространились на большой территории и существовали как ведущие типы геометрических микролитов до конца V тыс. до н.э.

Как ни удивительно, распространение геометрических микролитов со стругаными спинками мы фиксируем практически одновременно и в Передней Азии, и на юге Восточной Европы. Мы сделаем обзор самых ранних комплексов с микролитами указанных типов.

Саби Абьяд. Тель Саби Абьяд находится в долине реки Балих на юге Сирии. Исследовалась стоянка П. Аккерманом [4], изделия из камня обрабатывались Л. Коупленд [5, p.379-382; 6, p.285-338]. Нас интереСамарский научный вестник. 2014. № 3(8) сует раскоп 1, в комплексах которого были выявлены трапеции со стругаными спинками. На стоянке выявлены 11 археологических слоев позднего (керамического) неолита конца VII - первой половины VI тыс. до н.э. (табл.1), три из которых связаны с находками указанных изделий.

Одно изделие найдено на границе слоев 10 и 9, это высокая трапеция, изготовленная из медиальной части пластины, с неретушированными краями, с чешуйчатой ретушью на дорсальной поверхности, а также с двумя негативами струйчатых сколов. Ретушь частично покрывает спинку изделия. Отсутствие серии подобных трапеций позволяет предполагать, что имело место перераспределение материалов из верхних слоев.

Наиболее интересным для нас является факт нахождения скопления из 56 трапеций в углу комнаты жилища 1 слоя 5. Л. Коупленд почему-то описывает типологию 55 из них. Приведенный ниже перечень адаптирован к тем принципам классификации, которые указаны выше.

«Вытянутые типы» с бифациальной ретушью (21 экз.). К сожалению, мы не всегда можем по публикациям понять, насколько часто для изготовления микролитов этой группы использовались медиальные части пластин. Во всяком случае, среди изделий данной группы однозначно присутствуют изделия, изготовленные из целых, перовидных в профиле, пластин. Рабочим краем у таких изделий служил прямоугольный дистальный конец. Ретуширование дорсальной поверхности трапеций осуществлялось таким образом, что чешуйчатая и струйчатая ретушь покрывала ее практически полностью. Вентральная сторона могла ретушироваться подобным образом или иметь полукрутую чешуйчатую ретушь по краям, не смыкающуюся в центре изделия. Одна из трапеций имеет широкое основание, скошенное относительно продольной оси заготовки. Параметры изделий: ширина - до 1,2-1,3см, высота - до 3,8 см, толщина - до 4 мм.

«Подпрямоугольные типы» (25 экз.). Это высокие трапеции. Описание формы как прямоугольной, на наш взгляд, не соответствует действительности, форма микролитов на самом деле трапециевидная, как и у изделий первого типа. Также присутствуют изделия на целых пластинах. Большинство же трапеций - на медиальных частях пластин. Дорсальные стороны практически полностью покрыты чешуйчатой и струйчатой ретушью. Практически всегда края изделий подвергались дополнительной обработке, полукрутая краевая ретушь полностью уничтожала следы изломов заготовок. Полукрутая ретушь, как правило, наносится по сторонам трапеций и с вентральной стороны. Параметры изделий: ширина - до 1,2-1,3 см, высота - до 3,2 см, толщина - до 4 мм.

«Малые трапеции» (9 экз.). Я назвал бы такие трапеции средневысокими, все они - на медиальных частях пластин. Примерно половина таких трапеций имеют полукрутую вентральную ретушь по сторонам, прочие - со сторонами со следами изломов. У большинства трапеций чешуйчатая и струйчатая ретушь покрывает почти полностью дорсальную поверхность, хотя и имеются экземпляры, имеющие ретушь, лишь заходящую на спинку, не достигающую середины изделия. Параметры изделий: ширина - до 1,2-1,3см, высота - до 2 см, толщина - до 2 мм.

Трапеции также найдены в слое 4 Саби Абьяда, где найдены три экземпляра третьего типа. Две трапеции - с ретушью, заходящей на спинку, со следами изломов по сторонам. Одна трапеция - с круто ретушированными краями. Все трапеции изготовлены из медиальных частей пластин. Найдена одна заготовка трапеции, у которой на одном из краев нанесена полукрутая вентральная ретушь. Параметры изделий: ширина - до 2cм, высота - до 1,5 см, толщина - до 2 мм.

Как видим, типология трапеций, приведенная Л. Коупленд, основана на нетрадиционной системе, не 
учитывает те критерии типологизации, которые указаны в начале статьи. Мы привели описание геометрических микролитов Саби Абьяда в соответствии с этими критериями.

Мы увидели, что все изделия являются трапециями. По видам используемых заготовок мы отмечаем наличие целых пластин и их медиальных частей. Использование отжимной техники для получения заготовок не отмечено. Вообще во всех 11 слоях Саби Абьяда отсутствуют нуклеусы от отжимных пластин и сколы, полученные отжимным способом. По отношению продольной оси к широкому основанию мы констатируем перпендикуляр (для трапеций из целых пластин), параллель (для трапеций из медиальных частей пластин), в отдельных случаях - угловое расположение. По параметрам мы отмечаем наличие всех трех возможных вариантов: высокие, средневысокие, низкие трапеции. Следует отметить корреляцию средневысоких и низких типов с трапециями с изломами по сторонам. Для ретуширования с дорсальной стороны использовалась одновременно чешуйчатая и струйчатая ретушь. По виду ретуширования дорсальной поверхности мы констатируем наличие двух возможных типов, то есть дискретное ретуширование (ретушь, заходящая на спинку) и ретуширование, пересекающееся в центре и занимающее большую часть дорсальной поверхности. Для высоких и средневысоких типов отмечено полное ретуширование вентральной поверхности по аналогии с дорсальной, а также серийность в использовании полукрутой ретуши. Случаи наличия изломов на сторонах трапеций зафиксированы для средневысоких и низких экземпляров. Случаи ретуширования короткого основания не зафиксированы.

В целом невозможно не заметить типологическое разнообразие трапеций со стругаными спинками Саби Абьяда. Здесь мы встречаем микролиты всех пропорций, изготовленные с использованием разных технологий, из разных типов заготовок, в том числе таких необычных, как целые пластины. Сразу отметим, что последнее является уникальным приемом, до сих пор неизвестным в Восточной Европе. Учитывая раннюю хронологическую позицию комплексов Саби Абьяда, мы предполагаем, что типологическое разнообразие дает нам возможность реконструкции истории изобретения типа трансверсального наконечника со струганой спинкой.

В нашем случае такая реконструкция основывается на изучении истории отдельных технологических приемов, которые использовались для изготовления новых форм геометрических микролитов. Такими приемами были: получение заготовок для изготовления трапеций, использование полукрутой вентральной и плоской отжимной ретуши.

Для изготовления геометрических микролитов Саби Абьяда, гак говорилось, использовались два типа заготовок. Пластины с прямоугольными дистальными концами, которые использовались для изготовления трапеций сверхвысоких пропорций совершенно не свойственны для более поздних комплексов. Те изделия, которые изготовлялись из них, являются, вероятно, реликтовой переходной формой от черешковых колющих наконечников на пластинах к трансверсальным наконечникам. Примечательно, что подобные заготовки демонстрируют корреляцию с наличием полукрутой вентральной ретуши. Таким образом, логично предполагать, что поиск прототипов таких изделий должен быть связан с комплексами, в которых подобная корреляция была отмечена до появления типа трапециевидных наконечников со стругаными спинками.

Подобные изделия нам известны. Имеются ввиду так называемые «upsilon blades», известные нам по бореальным комплексам докерамического неолита В (PPNB) По определению С. Келли [7, p.87-92], морфология «uрsilon blades» характеризуется наличием на дорсальной поверхности негативов сколов, свидетельствующих о снятии пластины с биполярного нуклеуса; наличие граней дорсальной поверхности в виде греческой буквы «Ү»; прямоугольным, перовидным в профиле дистальным концом. Большое внимание «upsilon blades» вызвали после раскопок комплекса PPNB Хайаз Хююк на склонах Тавра на территории Турции [8, р.91-101]. Исследование этих удивительных изделий с вторичной обработкой в виде полукрутой ретуши с вентральной стороны показало, что на ретушированных краях присутствуют следы битума. Повреждения поверхности свидетельствуют об использовании «upsilon blades» в качестве вкладышей сложных орудий. Наличие макроизноса дистальных концов таких пластин в виде резцовых сколов позволяют сделать вывод об использовании их в виде трансверсальных наконечников [9, p.83].

По наблюдениям С. Келли, «upsilon blades» pacпространены на Ближнем Востоке в комплексах, связанных с биполярным расщеплением [7, p.87-92]. Но, как выяснил О. Барзилаи [10, p.59-72], наличие «upsilon blades» связано со специфической системой бипродольного расщепления ладьевидных нуклеусов. Всего исследователь различает три системы: «один на один», «обычная - епсилон» и «обычная с доминирующей платоформой». Первая связана с комплексами ранней PPNB и характеризуется встречным снятием пластин с точечными дистальными концами. Последняя известна только в негевских комплексах и используется для получения удлиненных пластин, характеризуется очень низкой эффективностью.

Метод же, связанный с получением «upsilon blades» характеризуется поочередным снятием длинных с острым дистальным концом пластин и «upsilon blades». Этот метод, по мнению О. Барзилаи, появляется на стадии средней PPNB и широко распространяется в период поздней PPNB. Комплексы с интересующими нас изделиями известны в Галилее и на севере пустыни Негев, а также на юго-западе Турции.

Традиция изготовления «upsilon blades» не прекращается с исчезновением PPNB. О. Барзилай и Й. Гарфинкель [11, p.27-31] приводят примеры бипродольного расщепления в комплексах PPNC и в ранних ярмукских комплексах. Особенно ценным для нас является констатация наличия бипродольного расщепления и наличия «upsilon blades» в раннеярмукском комплексе Шаар Хаголан в долине реки Иордан, поскольку этот комплекс является фактически синхронным с Саби Абьядом.

Вопрос о наличии бипродольного расщепления в Саби Абьяде решается, к сожалению, только на основе факта наличия пластин, снятых с двуплощадочных нуклеусов. Формы и размеры таких пластин позволяют допускать возможность их снятия с ладьевидных нуклеусов. Нуклеусы же данного типа не найдены, что и н удивительно при бедности комплексов. Отдельные находки бипродольных нуклеусов здесь связаны с финальной стадией расщепления, когда последние сколы уничтожают фронт снятия пластин.

Важной чертой, которая объединяет все упомянутые комплексы от PPNB до керамического неолита, является наличие в них острий библоского и амукского типов [12, p.45], оформленных дорсальной струйчатой отжимной ретушью. При этом отжимная техника применялась лишь для оформления острий, но не для получения заготовок.

Все это позволяет сделать следующие выводы.

Все технологические компоненты, связанные с изготовлением трансверсальных наконечников со струганной спинкой, существовали отдельно в ряде комплексов средней и поздней PPNB, PPNC, раннего ярмука и в раннехалафских комплексах Саби Абьяда.

Формирование типа заготовки «upsilon blades» связано с комплексами средней PPNB, с появлением технологии поочередного снятия двух типов заготовок при расщеплении ладьевидного нуклеуса.

Развитие указанной технологии неизменно сопровоСамарский научный вестник. 2014. № 3(8) 
ждается использованием отжимной струйчатой ретуши для изготовления орудий.

Появление трансверсальных наконечников, изготовленных из «upsilon blades», связано с комплексом Хайяз Хююка поздней PPNB.

Появление трансверсальных наконечников (трапеций) со стругаными спинками появляется в период кризиса традиционной системы бипродольного расщепления, когда оно сохраняется как реликтовое в отдельных комплексах керамического неолита Ближнего Востока.

Хронология данного процесса представлена в таблице 1 .

Таблица 1 - Позднейший этап развития технологии «обычная - епсилон» 「13]

\begin{tabular}{|c|c|c|c|}
\hline $\begin{array}{l}\text { Комп.екс, матершалд д.я } \\
\text { датшрованшя }\end{array}$ & Индекс лаб̆. & BP (uncal) & BC (CalPal) \\
\hline Хайяз Хюююк, уголь & GrN-12512 & $8040 \pm 170$ & $6991 \pm 247$ \\
\hline Хайяз Хююк, уголь & GrN-12510 & $8300 \pm 60$ & $7348 \pm 103$ \\
\hline Шаар Хаголан, уголь & OxA-7884 & $6980 \pm 100$ & $5867 \pm 98$ \\
\hline Шаар Хаголан, уголь & OxA-7920 & $7245 \pm 50$ & $6129 \pm 62$ \\
\hline Шаар Хаголан, уголь & OxA-7885 & $7270 \pm 80$ & $6144 \pm 75$ \\
\hline Шаар Хаголан, уголь & OXA-7917 & $7410 \pm 50$ & $6304 \pm 57$ \\
\hline Шаар Хаголан, уголь & OxA-7918 & $7465 \pm 50$ & $6335 \pm 61$ \\
\hline Шаар Хаголан, уголь & OxA-7919 & $7495 \pm 50$ & $6351 \pm 66$ \\
\hline Саб̆н Аб̆ьяд, слой 4 , уголь & UtC-1008 & $6930 \pm 80$ & $5828 \pm 80$ \\
\hline $\begin{array}{l}\text { Сабн Абьяд, слой 6, } \\
\text { обугленные зерна }\end{array}$ & GrN-19367 & $7025 \pm 25$ & $5935 \pm 36$ \\
\hline $\begin{array}{l}\text { Саби Абьяд, слой } 4 \text {, } \\
\text { обугленные зерна }\end{array}$ & GrN-16803 & $7075 \pm 30$ & $5960 \pm 34$ \\
\hline $\begin{array}{l}\text { Саб̆ Абьяд, слой } 8 \text {, } \\
\text { обугленные зерна }\end{array}$ & UtC-1009 & $7080 \pm 80$ & $5949 \pm 74$ \\
\hline $\begin{array}{l}\text { Сабин Абьвд, слой } 6, \\
\text { обугленные зерна, }\end{array}$ & GrN-19368 & $7100 \pm 60$ & $5974 \pm 53$ \\
\hline Саб̆н Аб̆ьяд, слой 8, уголь & GrN-16805 & $7145 \pm 30$ & $6027 \pm 20$ \\
\hline $\begin{array}{l}\text { Саби Абььдд, слой } 7, \\
\text { обугленные зерна }\end{array}$ & GrN-28240 & $7190 \pm 55$ & $6084 \pm 63$ \\
\hline $\begin{array}{l}\text { Cаб̆н Аб̈ьяд, слой } 5 \text {, } \\
\text { обугленные зерна }\end{array}$ & GrN-28244 & $7190 \pm 60$ & $6088 \pm 68$ \\
\hline $\begin{array}{l}\text { Саби Абьвад, слой } 7 \text {, } \\
\text { обугленные зерна }\end{array}$ & GrN-24218 & $7240 \pm 50$ & $6125 \pm 64$ \\
\hline
\end{tabular}

Как видим, все технологические приемы, используемые для изготовления ранних типов трансверсальных наконечников со стругаными спинками, существовали на протяжении конца VIII и всего VII тыс. до н.э. Процесс синтеза отдельных элементов, воплощенный в появлении нового вида охотничьего вооружения, завершился в конце VII тыс. до н.э. в раннехалафских комплексах. Традиционная технология бипродольного расщепления, связанная с историей изобретения типа, в указанное время переживала кризис, стояла на пороге исчезновения. Именно действие данного фактора привело к синхронному появлению реплик изделий, для изготовления которых использовался уже иной технологический цикл. Репликация, связанная с использованием заготовок, снятых с одноплощадочных подконических нуклеусов, привела к появлению классических трапеций со стругаными спинками, изготовленных из медиальных частей пластин.

Опыт изучения геометрических микролитов Саби Абьяда позволяет нам реконструировать историю происхождения определенного типа охотничьего вооружения и установить ее связь с началом репликации достигнутого результата. Забегая вперед, мы отметим, что анализ других комплексов не дает нам подобной возможности. По этой причине мы имеем право сделать предположение о том, что дальнейшее распространение геометрических микролитов со стругаными спинками связано с распространением культурных достижений раннего халафа, когда население, усваивающее инновацию, пользовалось готовым результатом.

Особенный статус Саби Абьяда подтверждается анализом синхронных комплексов с геометрическими микролитами со стругаными спинками.

Гиржево. Стоянка Гиржево исследовалась в 19621964 гг. П.И. Борисковским [14, с.1] и В.Н. Станко [15, c.96-103]. Данные о стратиграфии стоянки фрагментарны, однако есть оценки слоя с находками каменного века как результат неоднократного посещения. Учитывая, что такие материалы находились и в делювиальном суглинке зеленоватого цвета (до глубины $80 \mathrm{~cm}$ ), и в сером суглинке (до глубины 30 см), мы присоединяемся к мнению о многослойности памятника. Между тем хронологическая лакуна между комплексами, происходящими из разных литологических слоев, была не очень велика. Даты комплекса, полученные по костям, Самарский научный вестник. 2014. № 3(8) демонстрируют интервал в 340 радиокарбонных лет, а даты по керамике находятся приблизительно в середине этого интервала (табл. 2). Для нас это очень важно. Именно с неолитическим слоем, полученным при раскопках слоя серого суглинка, связана серия трапеций со стругаными спинками, а в этом слое найдено 10 из 12 таких изделий $[17$, с.98]. С этим же слоем связаны и находки неолитической керамики, показавшие возраст в рамках последней четверти VII тыс. до н.э., то есть синхронность с комплексами Саби Абьяда.

Таблица 2 - Радиокарбонные даты стоянки Гиржево 「16]

\begin{tabular}{|c|c|c|c|}
\hline $\begin{array}{l}\text { Комплекс, матерпат для } \\
\text { датшрования }\end{array}$ & Индекс лаб̆. & BP (uncal) & BC (CalPal) \\
\hline Гнржево, кость & $\mathrm{Ki}-11240$ & $7390 \pm 100$ & $6991 \pm 247$ \\
\hline Гнржево, керамика & Ki-11241 & $7280 \pm 170$ & $7348 \pm 103$ \\
\hline Гиржево, керамика & Ki-11243 & $7200 \pm 220$ & $6991 \pm 247$ \\
\hline Гнржево, кость & Le- 1703 & $7050 \pm 60$ & $7348 \pm 103$ \\
\hline
\end{tabular}

Всего в Гиржево, как говорилось, 12 трапеций со стругаными спинками. Мы можем описать типологию данных изделий. Все трапеции изготовлены из медиальных частей пластин, полученных отжимным способом при расщеплении уплощенных монофронтальных бипродольных двуплощадочных нуклеусов. Все трапеции, за одним исключением, связаны с использованием чешуйчатой и струйчатой дорсальной ретуши, которая полностью сводит на нет фасетки излома заготовок, придавая готовому изделию сегментовидный профиль. У одной трапеции мы видим неретушированную сторону, но не исключено, что это просто сломанный экземпляр. Ретушью покрыты лишь дискретные участки дорсальной поверхности, когда ретушь лишь заходит на спинки. Лишь в двух случаях мы наблюдаем, что ретушь, нанесенная с двух сторон, наслаивается на середине. По пропорциям и формам мы можем различать.

Средневысокие асимметричные трапеции. Параметры: высота-1,6-2,0см, ширина-1,7-2,2см, толщина-0,2-0,3см.

Низкие симметричные трапеции. Параметры: высота 1,3-1,7cм, ширина - 1,7-2,5см, толщина -0,2-0,3cм.

Сравнение с Саби Абьядом показывает, что трапеции со стругаными спинками отличаются очень существенно. Во-первых, мы здесь наблюдаем широкое использование отжимной техники для получения заготовок. Бипродольное расщепление сохраняет свои позиции, но пластины получают методом попеременного изменения полюсности после получения серии заготовок. Ни одна из трапеций не несет следов предварительного полукрутого ретуширования сторон с вентральной стороны. Изломы заготовок полностью сводятся на нет плоской дорсальной ретушью и последующей подработкой плоскими чешуйчатыми сколами.

Таким образом, мы не можем говорить ни о возможности прямого влияния со стороны носителей традиций Саби Абьяда, ни о сходстве технологий сравниваемых комплексов. Мы можем говорить лишь о репликации трапеций Саби Абьяда либо даже о независимом развитии двух технологий, приводящих в итоге к получению аналогичного результата. Взвесив аргументы, мы не можем отдать предпочтение какой-либо гипотезе. Гипотеза о репликации не может быть принята, поскольку в этом случае мы должны иметь какие-либо свидетельства прямого контакта носителей двух индустрий. Таких свидетельств нет. Независимое развитие технологий можно было бы рассматривать, но синхронность Саби Абьяда и Гиржево делает такой вывод маловероятным. В этой связи напрашивается вопрос о возможности существования какой-то транзитной индустрии, которая могла бы нести утраченные в Гиржево черты. На первый взгляд, таш-аирская индустрия Крыма могла бы с успехом выполнять такие «транзитные» функции. Попробуем разобраться с этой проблемой на примерах стратифицированных комплексов Таш Аир I, Шан-Коба (слой 1a).

Таш-Аир I и прочие неолитические комплексы крыма. Стоянка Таш-Аир I расположена под скальным навесом и на прилегающих к нему открытых участках правого берега реки Кача в Бахчисарайском районе. Стоянка 
исследовалась в 1938-40 гг. Д.А. Крайновым [18]. На стоянке автор отметил наличие 9 основных слоев, нижние из которых (IX-Va) связаны с неолитом. Таш-аирская индустрия прекрасно описана А.А. Яневичем [19], что избавляет нас от необходимости подробно описывать все ее особенности. Отметим лишь, что расщепление осуществлялось отжимным способом и наиболее распространенным типом нуклеусов был двуплощадочный уплощенный монофронтальный, то есть тип, являвшийся ведущим в гребениковской индустрии. Основное внимание мы ужелим анализу комплексов геометрических микролитов.

Слой IX - комплекс маловыразителен и геометрических микролитов не содержит.

Слой VIII. Д.А. Крайнов указывает на наличие семи геометрических микролитов, однако включает в эту серию одну «заготовку», медиальную часть пластинь трапециевидной формы. Описание изделий в публикации $[18$, с.22-23] не отражает реальности. Указания на оформление микролитов притупляющей ретушью противоречат реальной картине. Также нельзя согласиться с общим описанием микролитов таш-аирской индустрии, предложенным А.А. Яневичем [19, с.73]. Те же микролиты, ретушь которых описана Д.А. Крайновым как притупляющая, описывается как плоская. Это тоже не так. Две трапеции связаны с использованием струйчатой ретуши, как и у трапеций из Гиржево, которая по своему характеру не является ни крутой, ни плоской Это объемная ретушь, которая определяет наличие сегментовидного профиля в сечении трапеций, сделанного по продольной оси заготовок. Такая ретушь покрывает дискретные участки дорсальной поверхности. По сторонам также отмечено наличие фасеток мелкой полукрутой ретуши. У одной из описанных трапеций - мелкая полукрутая чешуйчатая ретушь на верхнем основании. Еще у одной трапеции стороны оформлены только полукрутой ретушью, струйчатая ретушь отсутствует. Такая же ретушь - на верхнем основании. Все трапеции - низкие симметричные. Параметры трапеций: высота - до 1,5 см, ширина - до 3,2 см, толщина - ок. 0,3 см. Полукрутой ретушью по дуге оформлены и три сегмента из описываемого комплекса. Все они также низкие симметричные. Параметры сегментов: высота: до 1,1 см, ширина - до 2,5 см, толщина - ок. $0,3 \mathrm{~cm}$.

Слой VII. Д.А Крайнов [18, с.58] упоминает 16 геометрических микролитов, на самом деле три из них таковыми не являются. Трапеций -9 , сегментов -4 , все - на медиальных частях пластин. Отличительная особенность серии - стилевое единство в применении ретуширования. Ни один из микролитов не связан с использованием струйчатой ретуши, когда длина фасетки более чем в два раза превышает ширину. Некоторые экземпляры демонстрируют ретушь, близкую к струйчатой, но все же мы должны охарактеризовать ретушь на всех микролитах как чешуйчатую полукрутую. Все микролиты - низкие симметричные, 4 трапеции имеют полукрутую ретушь на верхнем основании, в том числе дважды с дорсальной стороны и дважды - с вентральной. Крайне любопытна одна из трапеций. На одной из сторон мы отмечаем наличие двусторонней ретуши. При этом на вентральной стороне заретуширован скол макроизноса в виде резцового скола вдоль стороны микролита. Параметры трапеций: высота - до 1,5 cм, ширина - до 2,5 см, толщина - ок. 0,3 см. Параметры сегментов: высота - до 1,2 см, ширина - до 2,2 см, толщина - ок. 0,3 см.

Слой VI. В комплексе 13 геометрических микролитов, в том числе один обломок. Серия из 4 сегментов абсолютно аналогична сегментам слоя VII. А вот в серии трапеций (8 экз.) мы наблюдаем некоторые новые черты. Наряду с низкими трапециями появляются 2 средневысоких. В целом же стиль ретуширования сторон остается неизменным. У половины трапеций мы можем формально отметить наличие струйчатой ретуши, хотя соотношение длины и ширины сколов часто находится 140 на грани возможности подобного формального определения. У четырех трапеций ретушь полукрутая чешуйчатая, близкая к струйчатой. Один геометрический микролит - низкий ромб со струйчатой ретушью по сторонам, покрывающей дискретные участки дорсальной поверхности. Параметры трапеций: высота - до 1,7 см, ширина - до 2,5 см, толщина - ок. 0,3 см. Параметры сегментов: высота - до 1,2 см, ширина - до 2,6 см, толщина - ок. 0,3 см. Ромб: высота - 1,4 см, ширина - больше $2 \mathrm{~cm}$, толщина - ок. $0,3 \mathrm{~cm}$.

Комплексы слоев VIII-VI, как уже говорилось, связаны с ранним неолитом. Как мы увидели, отличительной особенностью этих комплексов является их связь с самым простым способом плоского ретуширования, когда длина негативов струйчатой ретуши невелика, когда ретушируются лишь дискретные участки дорсальной поверхности. По этим параметрам мы можем судить о хронологической близости геометрических микролитов Гиржево и ранних комплексов Таш-Аира I. Важным различием в комплексах указаных стоянок является наличие в крымских комплексах серий сегментов, отсутствующих в гиржевском комплексе. В то же время мы отмечаем полную тождественность трапеций со стругаными спинками. Причем данная тождественность связана как с типологическими характеристиками микролитов, так и с технологией их изготовления. И гиржевские, и таш-аирские микролиты - сегментовидные в сечении.

Где же микролиты появились раньше? Отсутствие радиокарбонных дат ранних таш-аирских комплексов не позволяет нам дать четкий ответ на этот вопрос. Косвенные же данные свидетельствуют об относительно более раннем возрасте крымских микролитов. Вопервых, мы видим в крымских комплексах серии сегментов, прообразы которых мы находим в поздних комплексах шан-кобинской индустрии. В частности, в слое 6/5 Фатьма Кобы известна серия сегментов с полукрутой ретушью, датирующихся серединой VIII тыс. до н.э. (табл.3). Во-вторых, геометрические микролиты ранних комплексов Таш-Аира I сопровождают серии пластинок с притупленными краями, происхождение которых, несомненно, кукрекское. Поздние кукрекские комплексы датируются началом-серединой VII тыс. до н.э. (табл.3). В то же время мы можем рассматривать и гипотезу об одновременном распространении геометрических микролитов со стругаными спинками как в Крыму, так и в Северо-Западном Причерноморье.

Последнее представляется весьма вероятным, поскольку в обоих случаях мы наблюдаем своего рода наложение новой инновационной технологии на технологию традиционную. Традиционные формы сегментов и трапеций сосуществуют с таковыми с дорсальной струйчатой ретушью. Не исключено, что инновации связаны с воздействием какой-то третьей индустрии, локализовать которую можно лишь определив технологию, используемую для изготовления новых типов микролитов. Проблемой технологии изготовления геометрических микролитов таш-аирской культуры занимался Д.Ю. Нужный $(1$, с.74). Выдвинутая им теория является достаточно аргументированной, но не может объяснить многие загадочные исключения.

Таблица 3 - Радиокарбонные даты, связанные с развитием таш-аирской индустрии [16; 21]

\begin{tabular}{|c|c|c|c|}
\hline $\begin{array}{l}\text { Комплекс, матершат д.ля } \\
\text { датшрованшя }\end{array}$ & Индекс лаб̆. & BP (uncal) & BC (CalPal) \\
\hline $\begin{array}{l}\text { Фатьма-Коба, шан-кобонская, } \\
\text { слой } 5 / 6 \text {, кость }\end{array}$ & Ki-10396 & $8520 \pm 150$ & $7581 \pm 186$ \\
\hline $\begin{array}{l}\text { Фатьма-Коба, шан-коб̆ннская, } \\
\text { слой } 5 / 6, \text { кость }\end{array}$ & Ki-11241 & $8770 \pm 140$ & $7909 \pm 218$ \\
\hline Мыс Троицы, кукрекская, кость & Ki-6340 & $7450 \pm 70$ & $6326 \pm 68$ \\
\hline Мыс Троицы, кукрекская, кость & Ki-6341 & $7800 \pm 60$ & $6630 \pm 71$ \\
\hline Кукрек, кукрекская, уголь & Bln-1799-2 & $7285 \pm 70$ & $6152 \pm 68$ \\
\hline Кукрек, кукрекская, уголь & \begin{tabular}{|ll} 
Ki-6341 & \\
\end{tabular} & $7320 \pm 65$ & $6180 \pm 73$ \\
\hline
\end{tabular}

Теория Д.Ю. Нужного о способе изготовления трапеций со стругаными спинками в комплексах ташаирской культуры. Д.Ю. Нужный полагал, что в процессе изготовления трапеций таш-аирской индустрии необходимым этапом было оформление сторон трапеСамарский научный вестник. 2014. № 3(8) 
ций полукрутой ретушью со стороны брюшка $[1$, с.78]. Именно такое оформление создавало площадку для дальнейшего плоского ретуширования дорсальной поверхности микролита. Д.Ю. Нужный даже отмечает наличие полуфабрикатов для трапеций со стругаными спинками, у которых дорсальная ретушь отсутствует, но уже присутствует полукрутая вентральная ретушь по сторонам. Мы полностью разделяем изложенную точку зрения, однако обязаны сделать это с существенными оговорками.

Дело в том, что свои выводы Д.Ю. Нужный сделал, в основном анализируя материалы слоя 1а стоянки ШанКоба. Но дело в том, что радиокарбонная дата этого слоя свидетельствует о том, что комплекс датируется $\mathrm{V}$ тыс. до н.э., не связан с ранними стадиями развития таш-аирской индустрии (табл.3). По типологии микролитов указанный комплекс близок к слою 5а стоянки Таш-Аир I, связанной с позднейшим неолитом Крыма. Проблема же состоит в том, что в ранних комплексах геометрические микролиты с вентральной полукрутой ретушью отсутствуют, как и в комплексе Гиржево, связанном с таш-аирской технологией изготовления трапеций со стругаными спинками. Мы могли бы допустить мысль, что небольшая статистическая выборка препятствует нахождению как заготовок, так и готовых изделий с неликвидированной площадкой, оформленной вентральной ретушью. Но, к сожалению, данный аргумент не может быть принятым.

Большое количество микролитов со стругаными спинками было найдено в ходе исследований Л.Г. Мацкевого [20, с.30-32]. Не все открытые им комплексы равнозначны, но нас интересует статистика. На 136 микролитов со стругаными спинками, происходящих из 13 комплексов Восточного Крыма, приходится лишь одна заготовка из слоя 1 стоянки Ленинское I. Мы не будем судить о хронологической позиции комплексов Восточного Крыма, они относятся к разным хронологическим этапам неолита. Важно то, что традиция, описанная Д.Ю. Нужным, едва ли являлась единственной и во всяком случае не являлась доминирующей. Судя по тому, что в только в поздних комплексах мы имеем значимые серии трапеций с вентральной ретушью (4 трапеции в слое 1а Шан-Кобы, 10 трапеций в материалах стоянки Балин Кош), мы вправе предположить, что данная традиция возникла в конце неолита, но ни в коем случае не в его начале.

Можем ли мы найти подтверждение данной гипотезы в археологических материалах соседних территорий? Можем. Мы в состоянии локализовать источник распространения технологии, связанной с вентральным полукрутым ретушированием сторон трапеций и дуг сегментов.

Памятники сероглазовского круга индустрий. Такие индустрии связаны с территорией Нижнего Подонечья, Нижнего Дона, Северного Прикаспия, Черноморского побережья Кавказа, Северного Кавказа. Мы впервые используем термин «сероглазовский круг индустрий», подразумевая сумму индустрий, связанных с мезолитом и неолитом, характеризующихся наличием геометрических микролитов с «гелуанской» ретушью. Существующие радиокарбонные даты позволяют связывать подобные индустрии с концом бореала - первой половиной атлантикума (табл.4). Отдельные индустрии, относимые к сероглазовскому кругу, были описаны автором в 2006 году, тогда же была предпринята попытка объяснить происхождение и развитие индустрий с сегментами столь необычной для Восточной Европы формы [16].

Все эти индустрии весьма различаются по типологическому составу изделий с вторичной обработкой. Только в Северном Прикаспии известно три типа сероглазовских индустрий на докерамическом этапе развития [22, с.3-41]. Многообразие вариантов сероглазовских индустрий сохраняется и на керамическом этапе. Также важно, что среди памятников сероглазовского Самарский научный вестник. 2014. № 3(8) круга присутствуют многослойные стоянки, иллюстрирующие тенденции развития отдельных типов орудий. Но интересны и отдельные комплексы, появившиеся в результате сборов подъемного материала. В частности, таковыми являются практически все некерамические комплексы.

Сероглазовские стоянки без керамики. Мы намеренно не пишем о мезолитической сероглазовской культуре, поскольку есть весьма существенные причины сомневаться в том, что сероглазовские памятники существовали вне рамок неолита. Об этом автор писал в 2006 г. [16], поэтому нет причин снова возвращаться к этому вопросу. Не исключено, что керамика просто не сохранялась на таких стоянках, однако следует признать, что типология геометрических микролитов подобных комплексов близка к типологии трапеций и сегментов из нижних слоев стоянок с керамикой.

В настоящее время известны три варианта сероглазовской докерамической индустрии: истайский, жекалганский и харбинский [22].

На стоянке Харба, давшей название одноименному варианту сероглазовской культуры, опубликованной П.М. Кольцовым [23], были найдены 13 сегментов и 7 трапеций. Вентральная ретушь здесь отмечена лишь на серии низких удлиненных сегментов, такая ретушь покрывает лишь кончики изделий на стыке дуги с основанием. Сегменты обычных низких форм не имеют подобной ретуши, как и трапеции. Харбинские материалы [24, с.292], как представляется, иллюстрируют начальную фазу становления вентрального ретуширования геометрических микролитов.

Же-Калганский вариант также лучше всего характеризует эпонимный комплекс. Стоянка - одна из немногих, частично раскопанных, с установленной стратиграфической позицией культурного слоя. Материалы получены в результате раскопок небольшого останца и сборов материалов вокруг него. В целом комплекс производит впечатление гомогенного. В материалах Же-Калгана среди сегментов преобладают низкие симметричные с крутой ретушью по дугам, однако присутствует серия из трех сегментов с «гелуанской» ретушью. Отдельные обломки микролитов могли быть связаны с трапециями. Как бы то ни было, даже на таких обломках вентральная ретушь отсутствует. По сравнению с материалами Харбы техника вентрального ретуширования дуг сегментов более развита, сходство же заключается в игнорировании такого технологического приема при изготовлении трапеций.

Комплексы, связанные с истайским вариантом сероглазовской культуры, отличаются высокой долей трапеций в геометрических комплексах при наличии серий сегментов с «гелуанской» ретушью. Для нас интересны комплексы Шонай I и Суек-тэ, в которых найдены по одному экземпляру трапеций с вентральной ретушью. Не исключено, что истайские комплексы хронологически близки к комплексам керамического неолита, о которых речь пойдет ниже.

Джангар. Стоянка Джангар исследовалась с 1978 г. П.М. Кольцовым $[25 ; 26]$. Стоянка стратифицирована, исследовано 3 слоя керамического неолита. Нижний, третий, слой демонстрирует весьма близкие черты с геометрическими комплексами стоянок истайского варианта сероглазовской культуры. Прежде всего это заметно по большому количеству трапеций в комплексе. Всего найдена 21 трапеция при наличии 12 сегментов. Высока роль вентральной ретуши при оформлении геометрических микролитов. Двусторонняя ретушь по дуге отмечена у восьми сегментов, а также по сторонам у 5 трапеций. Мы впервые отмечаем серию трапеций, которые, не будучи связанными с использованием струйчатой ретуши, демонстрируют тот же принцип оформления, что и трапеции поздней таш-аирской индустрии. Соответственно, мы вправе предположить, что первоначально геометрические микролиты с вен- 
тральной ретушью не были жестко связаны с технологией отжимного ретуширования. Нам известна хронологическая позиция нижнего слоя Джангара (табл.4), это рубеж VII-VI тыс. до н.э., то есть то время, когда технология струйчатого ретуширования спинок геометрических микролитов уже существовала. Этот факт побуждает нас отбросить безоговорочное утверждение Д.Ю. Нужного о непременной связи технологии изготовления трапеций со стругаными спинками Крыма с технологией вентрального ретуширования. Вероятно, данная технология возникла в Крыму на основе синтеза уже имеющейся технологии с принесенной из Восточного Прикаспия.

Имеем ли мы свидетельства проникновения технологии двустороннего ретуширования микролитов в Крым? Несомненно. Сегменты с двусторонней «гелуанской» ретушью найдены в третьем и в первом слое стоянки Фронтовое 1 [20, с.68, с.77], в первом слое стоянки Ленинское 1, там же была найдена трапеция с вентральной ретушью [20, с.87]. Показательно, что все указанные изделия не связаны со струйчатой ретушью на дорсальной поверхности, хотя сопровождаются многочисленными находками геометрических микролитов со стругаными спинками.

Таким образом, материалы нижнего слоя Джангара дают нам возможность судить о том, что развитие первоначальной технологии плоского ретуширования в Крыму и в Северном Прикаспии развивались совершенно независимо, а факты наложения технологий связаны с поздним неолитом.

Материалы 2 слоя Джангара датируются второй четвертью VI тыс. до н.э., то есть находятся уже за хронологическими рамками нашей работы. Тем не менее, мы обязаны вспомнить материалы данного слоя хотя бы для установления времени появления геометрических микролитов с ретушью, заходящей на спинки. Таковые имеются и среди сегментов, и среди трапеций, все они имеют вентральное ретуширование. Вполне вероятно, что синхронно появляются подобные же изделия и в Крыму, постепенно вытесняя более раннюю технологию, связанную, вероятно, с поздней шан-кобинской традицией полукрутого ретуширования геометрических микролитов.

Варфоломеевка. Совсем иную технологию изготовления трапеций со стругаными спинками демонстрируют нам материалы многослойной стоянки Варфоломеевка. Стоянка исследовалась в 1987-1996 гг. А.И. Юдиным [27]. Исследовано 4 слоя неолита, нас в данном случае интересуют лишь два нижних слоя.

Нижний слой 3 напоминает нижний слой Джангара, хотя и имеет более раннюю хронологическую позицию. В Варфоломеевке мы видим то же сочетание сегментов и трапеций, широкое использование вентрального ретуширования микролитов, использование «гелуанской» ретуши. Диапазон радиокарбонных дат - от середины до конца VII тыс. до н.э. (табл.4). В комплексе нижнего слоя нет никаких элементов струйчатого ретуширования дорсальной поверхности.

Слой 2Б демонстрирует значительное изменение состава геометрических микролитов. Наряду с традиционными типами микролитов мы наблюдаем серию высоких трапеций со стругаными спинками, стороны которых носят следы изломов, не ретушированы. Сегментов с плоской ретушью нет вовсе.

Всего в слое 2Б найдено 9 таких трапеций, все они изготовлены из отжимных пластин, изломы которых являлись площадками для нанесения плоской струйчатой ретуши, смыкающейся на середине изделий. Фасетки струйчатой ретуши покрывают дорсальные поверхности трапеций практически полностью. Параметры: высота - до 2 см, ширина - до 1,8 см, толщина - до 0,3 см. Слой датируется концом VII - началом VI тыс. до н.э. (табл.4).
Таблица 4 - Радиокарбонные даты, связанные памят-

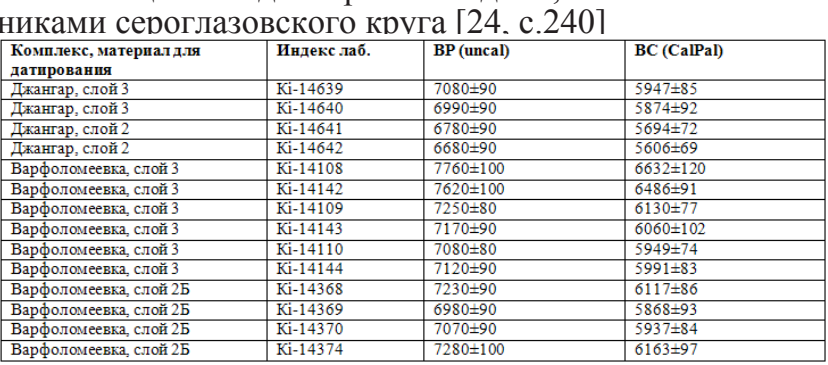

Как видим, трапеции со стругаными спинками в материалах Варфоломеевки появляются внезапно, демонстрируют наличие уже сложившегося типа, не имеющего прообразов в нижележащем слое. Подобное может свидетельствовать о том, что технология изготовления подобных трапеций привнесена извне, связана с функционированием устойчивых культурных связей с носителями другой каменной индустрии.

Мы не можем назвать такую индустрию, хотя параллели с отдельными геометрическими микролитами Саби Абьяда очевидны. Вполне возможно, что трасса распространения заимствований может привести нас, в конце концов, к Саби Абьяду. Но огромное расстояние, разделяющее Варфоломеевку и Саби Абьяд, позволяют нам предполагать, что существовали некие транзитные индустрии, о которых мы, к сожалению, сейчас ничего не знаем.

Таким образом, материалы слоя Джангара и Варфоломеевки позволяют сделать следующие выводы:

Геометрические микролиты со струганной спинкой появляются внезапно, об их ближневосточном происхождении позволяет говорить и типологическая близость с соответствующими изделиями Саби Абьяда, и тот факт, что такие микролиты представлены исключительно трапециями.

Дальнейшее распространение технологии струйчатого ретуширования дорсальных поверхностей геометрических микролитов связано с приспособлением традиционных технологий изготовления микролитов.

Приспособленная технология изготовления геометрических микролитов со стругаными спинками оказала влияние на развитие подобной технологии на территории Крыма.

Заключение. Таким образом, мы установили, что процесс широкого распространения геометрических микролитов со стругаными спинками начался в конце VII тыс. до н.э. и что одним из первичных центров распространения таких микролитов стало поселение Саби Абьяд на севере Сирии. Как выяснилось, практически одновременно изделия, находящие прямые аналоги в материалах Саби Абьяда, и их реплики распространяются на огромном пространстве юга восточной Европы от левобережья Волги до Поднестровья. При этом мы видим, что случаи прямого заимствования крайне редки. Фактически лишь материалы слоя 2Б Варфоломеевки дают нам подобные примеры. Все прочие случаи связаны с репликацией изделий. Так, население, оставившее ранние таш-аирские комплексы, приспособило новую технологию ретуширования к ранее практиковавшейся модели оформления дуг сегментов и сторон трапеций полукрутой ретушью. Так же репликация изделий со стругаными спинками произошла на правом берегу Волги в комплексе слоя 2 Джангара.

Феномен распространения геометрических микролитов со стругаными спинками показывает, что процессы усвоения инноваций в раннем неолите Восточной Европы происходили с необыкновенной скоростью, когда достижения новых технологий Ближнего и Среднего Востока практически одновременно становились известными на юге Восточной Европы, активно усваивались как на уровне копирования технологии, так и на уровне репликации, то есть приспособления традиционСамарский научный вестник. 2014. № 3(8) 
ных технологий.

Предпринятая попытка объяснения путей распространения новых технологий, в том числе и технологии изготовления геометрических микролитов со стругаными спинками, показывает информационное единство неолитического мира юга Восточной Европы, может пролить свет на проблему существования определенных векторов распространения отдельных культурных достижений, возникающих в первичных очагах неолитической революции.

Описанная картина не является полной. Не учтены материалы Ракушечного Яра и ряда других стоянок Нижнего Дона и Кавказа, поскольку существуют проблемы с реальной оценкой хронологии некоторых таких стоянок или проблемы с отсутствием качественных публикаций, что касается, в основном, Ракушечного Яра.

Остается нерешенным вопрос об источнике первичных технологий струйчатого ретуширования в раннем неолите Крыма, о возможности появления трапеций со стругаными спинками в Варфоломеевке в результате миграции.

Изложенные принципы оценки геометрических комплексов неолита юга Восточной Европы могут стать основой для дальнейшего исследования проблемы и реконструкции культурно-исторической картины на ранних этапах развития неолитических культур.

\section{СПИСОК ЛИТЕРАТУРЫ}

1. Нужний Д.Ю. Розвиток мікролітичної техніки в кам'яному віці: удосконалення зброї первісних мисливців. Київ: Вид-во КПТ, 2007. 306с.

2. Чабай В.П. Роль крымского микокА в поисках генетической подосновы костенковско-стрелецкой культуры // Археологический альманах. 2009. №20. С.129148.

3. Nadel D. The chipped stone industry from Netiv Hagdud. // O. Bar-Yosef and A. Gopher (eds.), An Early Neolithic Village in the Jordan Valley, Part I: The Archaeology of Netiv Hagdud -. American School of Prehistoric Research, Bulletin 44. Peabody Museum of Archaeology and Ethnology, Harvard University, Cambridge. 1997. P.71-149.

4. Tell Sabi Abyad - The Late Neolithic Settlement. Vol.1, 2. Ed. P.Ackermans. Leiden/Istanbul: Nederlands Historisch-Archaeologisch Instituut, 1996. 566 pp.

5. Copeland L., Ackermans P.M.M.G. A Cache of 56 Flint Transverse Arrowheads from Tell Sabi Abyad, Balikh Valley, Siria // Eds. Gebel A., Kozlowski S. NeolithicChipped Stone Industries of the Fertile Crescent. Berlin: ExOriente, 1994. P.379-383.

6. Copeland L. The flint and obsidian industries // Tell Sabi Abyad - The Late Neolithic Settlement. Vol.1, 2. Ed. P.Ackermans. - Leiden/Istanbul: Nederlands HistorischArchaeologisch Instituut, 1996. 566 pp.

7. Calley S. Some questions concerning upsilon blades // Anatolica. - 1988. - XV. P.87-92.

8. Roodenberg J. Hayaz Hoyuk and the final PPNB in the Taurus foothills // Paleoorient. - 1989. - Vol.15/1. P.91-102.

9. Ataman K. A preliminary analysis of the upsilon blade tools from Hayaz Hoyuk // Anatolica. 1988. XV. P.81-85.
10. Barzilai $\mathrm{O}$. The bidirectional blade industries of the Southern Levant // eds. Borell F., Ibanes J.J., Molist M. Stone Tools in Transition: From Hunter-Gatherers to Farming Societies in the Near East. Bellaterra: UABSP, 2013. P.59-72.

11. Barzilai O., Garfinkel Y. Bidirectional Blade Technology after the PPNB: New Evidence from Sha'ar Hagolan, Israel // Neo-Lithic. 2006. №1. P.27-31.

12. Gopher A. Neolithic arrowheads of the Levant: results and implications of a seriation analysis // Paleoorient. 1989. Vol.15/1. P.43-56.

13. Böhner U., Schyle D. Radiocarbon CONTEXT database 2002-2006. http://context-database.uni-koeln.de.

14. Борисковский П.И. Разведки памятников каменного века в Одесской области в 1962 году // Краткие сообщения Одесского археологического музея. Одесса, 1964. C.1-2.

15. Станко В.Н. Мезолитическая стоянка Гиржево в Одесской области (1962-1964г.) // Советская археология. 1966. № 2. С. 96-103.

16. Манько В.О. Неоліт Південно-Східної України. Київ: Шлях, 2006. 280с.

17. Сапожников И.В., Сапожникова Г.В. Каменный век Северо-Западного Причерноморья // Stratum plus. 2011. №1. С.15-152.

18. Крайнов Д.А. Пещерная стоянка Таш-Аир I как основа для периодизации послепалеолитических культур Крыма // Материалы и исследования по археологии СССР. 1960. №91. М.: Наука, 1960. 190с.

19. Яневич О.О. Таш-аїрська неолітична культура Гірського Криму // Кам'яна доба України. Вип.5. К.: Шлях, 2005. С.169-184.

20. Мацкевой Л.Г. Мезолит и неолит Восточного Крыма. К.: Наукова думка, 1977. 180с.

21. Zaitseva G.I., Timofeev V.I., Zagorska N.N., Kovaliukh N.N. Radiocarbon dates of the Mesolithic sites of Eastern Europe // Radiocarbon and Archaeology. 2000. I. P.33-52.

22. Васильев И.Б., Выборнов А.А., Комаров А.М. Мезолитические памятники Северного Прикаспия // Археологические культуры Северного Прикаспия. Куйбышев: Куйбышевский государственный педагогический институт, 1988. С.3-41.

23. Кольцов П.М., Эрдниев У.Э. Мезолитическая стоянка Харба на территории Сарпинской низменности // Проблемы хронологии археологических памятников Северного Кавказа. Орджоникидзе, 1985.

24. Выборнов А.А. Неолит Волго-Камья. Самара: Самарский государственный педагогический университет, 2008. 490c.

25. Кольцов П.М. Неолитическое поселение Джангар // Археологические культуры Северного Прикаспия. Куйбышев: Куйбышевский государственный педагогический институт, 1988. С.52-91.

26. Кольцов П.М Поселение Джангар. Человек и его культура в неолите Северо-Западного Прикаспия. Элиста: Новый хронограф, 2004. 156с.

27. Юдин А.И. Варфоломеевская стоянка и неолит степного Поволжья. Саратов: Изд-во Саратовского университета, 2004. 200c

\title{
THE BEGINNING OF SPREADING OF TECHNOLOGY OF MANUFACTURING OF GEOMETRIC MICROLITES WITH DORSAL FLAT RETOUCH
}

\section{(C) 2014}

\author{
V.A. Manko, Candidate of Historical Sciences, senior research fellow of Department of Crimean Archaeology \\ Institute of Archaeology, National Academy of Sciences of Ukraine, Kiev (Ukraine)
}

Annotation: The author analyzes the emergence and spread of geometric microliths with flat pressing dorsal retouch in the Near and Middle East, in the basin of the Eastern Mediterranean and in Eastern Europe. We consider the typology of these products and their role in the Neolithic complexes of Eastern Europe. Author makes analysis of the typology and technology of geometrics and detected primary and secondary centers of dissemination of new technology.

Keywords: neolithic; pressing flake production; geometric microlites with flat pressing dorsal retouch; microlites with Helwan retouch. 